\title{
Biopolítica y Reservas de la Biosfera: espacios de (in) movilidad y conflicto. Una mirada etnográfica ${ }^{1}$
}

\author{
Biopolitics and Biosphere Reserves: contentious (im) \\ mobility sites. An ethnographic approach
}

\author{
Matilde Córdoba AzCÁrate \\ Universidad Complutense de Madrid \\ m.cordoba@cps.ucm.es
}

Recibido: 16.02 .2012

Aprobado definitivamente: 02.10 .2012

\begin{abstract}
RESUMEN
Este artículo trabaja con el concepto de espacios de (in)movilidad para subrayar la centralidad de la movilidad en las discusiones sobre biopolítica. El articulo reúne evidencia etnográfica del estudio de las prácticas de conservación y desarrollo ecoturístico en la Reserva de la Biosfera Ría Celestún (Yucatán, México). A través del repaso etnográfico de dos disputas, el artículo muestra cómo el proyecto biopolítico asociado a la conservación de la biodiversidad y el desarrollo de un turismo de naturaleza, ha establecido la ría y la playa de la comunidad como dos espacios de (in)movilidad y conflicto donde no sólo los flujos globales (de personas, capital, trabajo) se condensan, sino donde determinados colectivos luchan por permanecer inmóviles apropiándose en su permanencia de los referentes de la biodiversidad para la defensa de intereses locales.
\end{abstract}

Palabras Clave: Biodiversidad; Biopolítica; Conservación; Desarrollo; Espacio; Movilidad; Turismo.

\begin{abstract}
This paper uses the concept of sites of contentious (im)mobility to highlight the centrality of mobility for bio-politics. The article draws ethnographic evidence from the study of conservation and ecotourism practices in the Biosphere Reserve of Ría Celestún (Yucatán, México). Through the ethnographic attention to two disputes, the article shows how the biopolitical project associated to the conservation of biodiversity and the development of nature tourism has transformed the ria and the beach into two spaces of contentious immobility in which global flows (of people, capital and labour) are condensed and in which specific groups fight to stay still. In so doing, these groups use the global referents of biodiversity for their own local interests
\end{abstract}

KEYwords: Biodiversity; Biopolitics; Conservation; Development; Globalization; Mobility; Space; Tourism.

\section{SUMARIO}

1.Introducción. 2.La Reserva de la Biosfera Ría Celestún (Yucatán, México) como proyecto biopolítico. 3.Espacios de (in)movilidad y conflicto. 4.Conclusiones

\footnotetext{
${ }^{1}$ Este trabajo es resultado del proyecto de investigación del Plan Nacional $\mathrm{I}+\mathrm{d}+\mathrm{i}$ "Turismo, Territorio y Nuevas Movilidades" (CSO2008-04941) y se ha desarrollado dentro del Programa Post-doctoral MICIIN-Fulbright en The Graduate Center, City University of New York (2010-2012). Actualmente la investigación está respaldada por el pro-
} 


\section{INTRODUCCIÓN}

Los discursos y prácticas de desarrollo, de conservación y turismo asociados a la biodiversidad son procesos contemporáneos clave en la re-estructuración del espacio y en la producción de nuevas formas de vida, conocimiento y relaciones sociales. En estos procesos de re-estructuración espacial y de producción biopolítica, la movilidad es un factor clave (Bergman y Sager, 2008; Mendiola, 2006; Park, 2003; Sevilla Buitrago, 2010; Sheller y Urry, 2004, 2006).

En el contexto de las discusiones sobre biopolítica, la biodiversidad, y concretamente su articulación a través de Reservas de la Biosfera, ha sido concebida como uno de los proyectos clave en el avance de procesos de globalización hegemónica (Escobar, 2008; Quijano Valencia y Tobar, 2006). En este contexto, se entiende que los discursos sobre biodiversidad funcionan a partir de tres conversiones semióticas cruciales a través de las cuales el proyecto biopolítico se materializa en la práctica. En primer lugar, la conversión de la naturaleza y los territorios en "reservas de valor" particular. En segundo lugar, la conversión de las poblaciones locales en "guardianes" de la biodiversidad. Y en tercer lugar, la articulación del saber o los conocimientos locales, como elementos necesarios para "salvar" la naturaleza (Escobar, 1996; 1998).

Este artículo analiza desde una perspectiva etnográfica basada en la Reserva de la Biosfera Ría Celestún (Yucatán, México) cómo estas conversiones semióticas, y fundamentalmente las dos primeras, están estrechamente articuladas en la práctica a través de un sistema de movilidades que genera en estas "reservas de valor" lo que voy a denominar como espacios de (im)movilidad ${ }^{2}$. Los espacios de (in)movilidad pueden ser definidos como esos nichos emergentes, de fronteras difusas, que en comunidades geográficas concretas son transformados en virtud a proyectos globales, como por ejemplo, la biodiversidad. Son nichos caracterizados por la dialéctica entre movilidad e inmovilidad o permanencia en el lugar; espacios social y medio-ambientalmente disputados y vulnerables que devienen asimétricamente hiper-conectados a los flujos internacionales. En estos espacios, los recursos globales y el capital se concentran y diferentes agentes pelean por permanecer inmóviles pues es la inmovilidad misma, la ocupación permanente del lugar, la que va a dictar el acceso y el control locales de estos recursos globales, y por ende, la posibilidad de beneficiarse de los mismos. Los espacios de (in)movilidad son espacios sometidos a fuertes disciplinamientos pero en ellos, como vamos a ver, es posible descubrir prácticas potencialmente creativas y generativas de cambio social.

La atención etnográfica a cómo se generan y qué acontece en estos espacios de (in)movilidad pone de manifiesto la centralidad de la movilidad en la articulación del proyecto biopolítico. Concretamente, revela cómo el ejercicio del poder sobre comunidades particulares no sólo se realiza a través de la imposición de restricciones sino también a través de la movilización de las poblaciones hacia nuevas prácticas, como por ejemplo, el turismo. Prestar atención a cómo tiene lugar esta movilización desde las prácticas mismas ilumina las discusiones sobre biopolítica en dos sentidos fundamentalmente.

En primer lugar, permite comprender desde una perspectiva micro cómo tiene lugar el gobierno del "milieu" y por ende, entender uno de los aspectos críticos de la producción biopolítica, la articulación de los dispositivos de poder y de saber que versan sobre una población concreta a lo largo del tiempo, sobre los "procesos de la vida" y sobre la posibilidad de controlarlos y transformarlos (Foucault, 2006, 2009). Como apuntara Foucault (2008: 29), en el gobierno del "milieu" lo importante no va a ser "establecer límites y fronteras, o fijar lugares, sino, sobre todo, y esencialmente, hacer posible, garantizar y velar por la circulación de las personas, las mercancías, y el aire, etc.”. Trazar etnográficamente la creación y regulación de espacios de (in)movilidad en un régimen biopolítico específico, como las Reservas de la Biosfera, resulta útil no sólo para

yecto de investigación del Plan Nacional $\mathrm{I}+\mathrm{d}+\mathrm{i}$ "Lugares, imaginarios y movilidades turísticas en tiempos de crisis" (CSO2011-265227).

${ }^{2}$ Una primera aproximación a este concepto aparece desarrollada en Córdoba Azcárate, M. (2010). 
comprender cómo tienen lugar esos procesos de codificación y regimentación de las relaciones entre diferentes especies (animales, vegetales, humanas), sino para observar cómo estos se traducen y se articulan en la práctica.

En segundo lugar, la atención situada a la producción de estos espacios de (in)movilidad resulta interesante para dar cuenta, siguiendo a Hardt y Negri $(2002,2004)$, de la potencialidad inherente a la producción biopolítica de generar formas de vida alternativas y confrontacionales con los sistemas hegemónicos. Estudiar cómo se generan en la práctica espacios de (in)movilidad y cómo estos devienen en algo más que micro espacios disciplinados resulta fundamental para abordar las propiedades emergentes y conflictivas de los procesos globalizadores, pero también, para comprender cómo fuerzas y políticas globales, en este caso asociadas a la biodiversidad, son apropiadas creativamente para responder a intereses locales.

El material etnográfico utilizado en este artículo forma parte de un trabajo de campo antropológico sobre movilidades turísticas, desarrollo y producción del espacio realizado en la Reserva de la Biosfera Ría de Celestún (Yucatán, México) durante los años 2005 y 2009.

La Reserva de la Biosfera Ría Celestún está situada entre los estados de Campeche y Yucatán y comprende las comunidades de Celestún y Maxcanú (Yucatán) y Calkini (Campeche). De ellas, Celestún reúne al $90 \%$ de la población que asciende a más de 6000 habitantes fundamentalmente dedicados a la pesca del pulpo y el camarón. El área tiene una larga trayectoria conservacionista que se remonta a 1979 y desde finales de los años 1990 las actividades ecoturísticas han sido sistemáticamente promovidas como vehículo de desarrollo alternativo a la pesca para el grueso de la población. Actualmente, la reserva comprende un área protegida de más de 80,000 hectáreas; forma parte de la Lista Ramsar de Humedales Protegidos de Importancia Internacional (2010) y de la lista de la UNESCO de Reservas de la Biosfera del Mundo (2009). El flamenco rosa que anida y se reproduce en las aguas de la Ría Celestún se ha convertido en el principal emblema de la biodiversidad del lugar pero también, en su principal atracción turística y en una de las imágenes más distribuidas que promocionan un México alternativo en el mercado turístico internacional. Tanto la conser- vación del área como su desarrollo ecoturístico han sido actividades promovidas institucionalmente desde los gobiernos federal y estatal y no han respondido a demanda alguna por parte de la población. Esta "imposición desde arriba" ha convertido el área en un espacio disputado y conflictivo.

Entre los problemas más importantes asociados a la implementación de medidas proteccionistas se han señalado por ejemplo, una relación conflictiva del personal de la Reserva con la comunidad; la existencia de un turismo sin control; un continuado crecimiento poblacional y graves problemas de contaminación ambiental derivados de la pesca y el turismo; el bloqueo del flujo de agua por la creación de carreteras y puentes y las constantes prácticas de saqueo de especies silvestres; una escasa participación local en los procesos de regulación del área; la ausencia de actividades productivas reales y una elevada restricción en el uso de los recursos naturales (Méndez Contreras et al., 2008). Por su parte, el desarrollo del ecoturismo como motor económico para la población no ha estado exento de problemas. Exclusivamente centrado en la observación del flamenco rosa en la ría de Celestún, el ecoturismo ha impuesto unas dinámicas espaciales concretas y ha generado unas nuevas jerarquías de poder local informadas por la cercanía o lejanía de la población local con respecto a los denominados como "turistas del paquete rosa". Como vamos a ver, la ria y la playa de la comunidad se han convertido en esos espacios de (in)movilidad donde diferentes colectivos (instituciones de desarrollo y conservacionistas, personal del gobierno, pescadores, guías turísticos, artesanas) luchan por permanecer inmóviles con la esperanza de acceder a los beneficios derivados de las actividades conservacionistas y de desarrollo turístico en el área. En estos espacios, nuevos agentes como los lancheros turísticos de la ría y las artesanas de concha y caracol de la playa, se han apropiado del espacio y de los discursos asociados a la biodiversidad del área convirtiéndose en los guardianes de los flujos globales de turistas, capital y trabajo que ésta ha generado, y por ende, de las alternativas productivas en la comunidad. La visibilidad de los conflictos protagonizados por estos colectivos de lancheros $\mathrm{y}$ artesanas, en estos espacios de la ría y de la playa, así como la naturaleza virulenta de los mismos, han llevado recientemente a denominar Celestún como el Afganistán de la costa maya. Prestar una atención 
etnográfica a cómo tienen lugar estos conflictos y determinar qué es lo que en ellos está en juego, pone de manifiesto el potencial transformador, "desde abajo" de las relaciones de poder-saber y de las dinámicas espaciales generadas por la Reserva de la Biosfera como un proyecto biopolítico concreto.

El artículo está organizado de la siguiente manera. La primera sección ofrece una pequeña contextualización de la génesis de la Reserva de la Biosfera Ria Celestun como proyecto biopolítico. Esta sección traza las actividades conservacionistas y ecoturísticas en el área con el objetivo fundamental de situar histórica, geográfica y socialmente la emergencia de los espacios de la ría y de la playa como esos espacios de (in)movilidad y conflicto. La siguiente sección analiza con detalle etnográfico dos disputas en cada uno de estos espacios respectivamente, y estudia las estrategias de lucha de determinados colectivos de la población por apropiarse de estos espacios y de sus recursos a través de inmovilizarse en ellos. Estas disputas ejemplifican por un lado, como tras un conflicto pesquero, parte de la población de Celestún cierra el espacio de la ría y suspende el uso de sus antiguos y nuevos recursos (camarones, flamencos y turistas) para locales y foráneos; y por otro lado, la competición diaria entre artesanas locales y artesanas chiapanecas por el control del espacio de la playa y su proximidad a los turistas. Las conclusiones ofrecen una síntesis de los argumentos centrales desarrollados en el artículo.

\section{LA RESERVA DE LA BIOSFERA RIA CELESTÚN (YUCATÁN, MÉXICO) COMO UN PROYECTO BIOPOLÍTICO.}

El desarrollo de las actividades de conservación y turísticas en Celestún están estrechamente ligadas a la declaración del área como Área Natural Protegida (1979/2000).

Las áreas naturales protegidas son ejemplos de lo que se ha llamado 'conservación in situ' (Robles de Benito, 2005: 12). Este tipo de conservación in situ posee como propósito fundamental "garantizar la conservación de la integridad de sus ecosistemas y las especies que los habitan a través de puestas a parte mediante disposiciones legales" (Ibíd. 16) como son por ejemplo, los Planes de Manejo. En aquellas áreas naturales protegidas en las que además existen comunidades insertas dentro de los límites protegidos, como es el caso de Celestún, y a nivel discursivo, la conservación in situ a través del establecimiento de Reservas de la Biosfera 'trata de sustituir (discursivamente) el paradigma de "conservar para usar", por el de "usar para conservar", o "usar conservando" (Ibíd.). Estas máximas dictan los nuevos códigos de ordenación de las relaciones entre diferentes especies animales, vegetales y humanas al tiempo que instauran unas nuevas fronteras entre estos regímenes de vida regulando a nivel local y de un modo novedoso las relaciones entre ellas. Son, como Escobar (2008) brillantemente ha estudiado, los nuevos dispositivos de colonización de la naturaleza a través de la institucionalización de una gestión cada vez más racionalizada del medio ambiente.

De acuerdo al Programa del Hombre y la Biosfera (UNESCO, 1979), las Reservas de la Biosfera son ecosistemas terrestres y costeros cuya principal meta es la de promover soluciones para la reconciliación de la conservación de la biodiversidad y sus usos sostenibles. Como entidades legales, las Reservas de la Biosfera son nombradas a nivel nacional y reconocidas posteriormente por un comité internacional y todas, mundialmente, deben cumplir con tres funciones fundamentales y complementarias que son: (1) una función de conservación para proteger los recursos genéticos, las especies, los ecosistemas y los paisajes; (2) una función de desarrollo, a fin de promover un desarrollo económico y humano sostenible; y (3) una función de apoyo logístico, para respaldar y alentar actividades de investigación, de educación, de formación y de observación permanente relacionadas con las actividades de interés local, nacional y mundial encaminadas a la conservación y el desarrollo sostenible (UNESCO, 1996: 4). Estas funciones se articulan en la práctica a través de los Planes de Manejo que, aunque específicos para cada Reserva de la Biosfera en cuestión, están orientados por la misma filosofía y siempre actúan a través de la zonificación del área protegida.

Los procesos de zonificación pueden considerarse como la materialización por antonomasia del proyecto biopolítico de las Reservas de la Biosfera a través del cual se legitima la instauración de nuevos regímenes de poder y control de las poblaciones. Los procesos de zonificación generalmente implican la reorganización de la tierra y sus usos con el obje- 
tivo declarado de "preservar la tierra y las especies con significación e importancia global en términos de biodiversidad" (UNESCO, 2009, sp).

Atendiendo a la zonificación propuesta por el Plan de Manejo de la Reserva de la Biosfera Ría Celestún, el área protegida de la misma comprende una superficie de 81,482,33 hectáreas distribuidas en tres zonas claramente demarcadas: una zona núcleo, que comprende el 37,2\% del área protegida y que coincide fundamentalmente con el espacio de la ría de Celestún, la mayor área de concentración de biodiversidad en la reserva; una zona de amortiguamiento que comprende el $62.8 \%$ del área protegida y que está subdividida en cinco unidades heterogéneas que varían de acuerdo con las condiciones ecológicas, sociales, de infraestructura o servicios. Dentro de esta zona de amortiguamiento, la unidad de aprovechamiento sustentable de los recursos naturales representa el $82.3 \%$ y está circunscrita a la ría y algunas partes de la playa. El resto del espacio está dividido entre una unidad de uso restringido, una unidad de uso público, una unidad de recuperación y una unidad de asentamiento humano que es donde se encuentra el $90 \%$ de la población de Celestún (Semarnat, 2000:9).

Esta zonificación, aunque muy clara en el papel es, sin embargo, desconocida por la mayor parte de la población en Celestún y así, aunque es un factor clave en la gestación de nuevas formas de gubernamentalidad en términos foucultianos, pone en duda aquellos planteamientos que verían una traducción inmediata y sin fricciones entre los mecanismos de generación institucional de saber-poder y las prácticas de control de las poblaciones. De acuerdo a un estudio de campo realizado en el año 2004 por una de las instituciones de investigación en el área, el $90 \%$ de la comunidad desconocía que habitaba en el seno de un área natural protegida. El 10\% que sabía algo al respecto, identificaba el área protegida con el espacio de la ría y con el flamenco rosa (Méndez Contreras et alii, 2008).

El desarrollo de las actividades ecoturísticas en la comunidad por parte del gobierno federal ha jugado un papel determinante como aliciente a esta situación de desconocimiento y ha venido además a complicar el tejido social de la comunidad de un modo ostensible. Va a ser precisamente a principios de la década de 1990 y ante una crisis deficitaria de grandes dimensiones, cuando comiencen a darse los primeros pasos en todo el territorio mexicano por convertir a las Áreas Naturales Protegidas en sitios de atracción turística, o, como recoge un miembro de Pronatura, en "zonas económicamente productivas a nivel nacional" (Andrade et alii., 1994:1). En la política turística mexicana, la Reserva de la Biosfera Ría Celestún se ha convertido en una parada obligada para un turismo de naturaleza y ha sido crucial en el camino de diversificar una región totalmente dependiente todavía del turismo de sol y playa de la costa de la Riviera Maya en el Caribe. Como parte de un proyecto del gobierno federal, el ecoturismo en Celestún se ha desarrollado bajo el manto discursivo de la necesidad de diversificación económica en aras de la preservación de la naturaleza. En la práctica, las actividades ecoturísticas han seguido sin embargo la lógica de los paquetes turísticos imperantes en la costa del Caribe Mexicano $\mathrm{y}$, sin responder a demanda alguna por parte de la comunidad, se han traducido en la realización de tours organizados en dos movimientos clave: la visita guiada en lancha por la ría para observar al flamenco rosa y la parada en un restaurante de la playa para comer pescado fresco.

Estas prácticas, totalmente institucionalizadas, han dado lugar a un sistema de movilidades de turistas, capital, trabajo y recursos muy definido en el tiempo y en el espacio dentro de la comunidad. Estos movimientos operan en lapsos de cinco horas de manera única entre los espacios de la ría y la playa dejando el resto de la comunidad y sus prácticasque crecen a ambos lados de la única avenida que comunica la ría y la playa- totalmente veladas a la mirada del turista, de las instituciones de desarrollo y de conservación. Estadísticamente, se estima que la Ría de Celestún recibe del orden de quince a veinte mil turistas al año (SEMARNAT, 2003: 36) y atendiendo a una encuesta realizada por Pronatura en 1999, el flamenco rosa destaca como el principal motivo $(94,54 \%)$ de la visita de los turistas al municipio. A pesar del elevado número de turistas que recibe la comunidad, fuera de los espacios de la ría y de la playa, y después de 20 años de conservación y más de 10 años de ecoturismo, este todavía falla en ser una alternativa económica real para la mayoría. El $80 \%$ de la población de Celestún todavía vive de la pesca; más del $40 \%$ de la población económicamente activa recibe menos que el salario mínimo (3,5 dólares al día); el 45\% de las casas usa 
la leña y el carbón para cocinar y menos del 33\% de las casas tienen un refrigerador. Tan sólo el 5,2\% de la población tiene acceso a servicios médicos y menos del $8 \%$ de la misma posee educación secundaria (INEGI, 2005).

Estar fuera de los espacios de la ría y de la playa significa estar brutalmente desconectado de los flujos globales y de sus beneficios. Por el contrario, estar entre estos flujos, en la ría, en la playa, otorga, como vamos a ver, el poder de beneficiarse, y también a veces, de reordenar estos recursos globales que circulan en la comunidad. Las instituciones de desarrollo y de conservación, las organizaciones no gubernamentales y sobre todo, la población local, luchan por apropiarse los espacios de la ría y de la playa como esos espacios de movilidad global a través precisamente de inmovilizarse en ellos. Las siguientes disputas ejemplifican cómo la ría y la playa emergen como estos espacios de (in)movilidad y conflicto donde se están originando nuevas alianzas de micro-poderes locales con el objetivo, muchas veces, de alterar y transformar el funcionamiento de la Reserva como proyecto biopolítico a nivel global.
Ambos casos nos permiten observar, desde prácticas concretas, cómo tiene lugar el gobierno de la biodiversidad en el día a día.

\section{ESPACIOS DE (IN)MOVILIDAD Y CONFLICTO}

\subsection{En la ría: "A la cárcel por pescar para comer"}

El siguiente conflicto tuvo lugar hace algunos años en la ría de Celestún. Tuvo tanto eco en la prensa nacional, regional y local que en la comunidad es todavía muy comentado y enarbolado como un ejemplo clásico de la situación conflictiva en la que vive la población. Narro el conflicto desde una serie de reconstrucciones literales de los hechos tomadas de la prensa local, de un artículo científico de un investigador del área y de una entrevista personal con uno de los protagonistas del conflicto realizada durante mi trabajo de campo en la comunidad.

El 23 de mayo de 2002, elementos de la Armada de México, estacionados en la Región Naval Militar de Campeche, detuvieron a nueve pescadores de Celestún, quienes capturaban camarón, especie en veda. Según la Armada, éstos se encontraban en la parte campechana de la ría, versión que los detenidos refutaron, argumentando que estaban dentro del territorio yucateco. Los pescadores, todos varones entre los 20 y 17 años de edad, fueron llevados al penal de San Francisco Kobén (Campeche) por capturar cuatro kilogramos de camarón, considerado un delito grave, ya que se realizó dentro de un área natural protegida, en este caso la Reserva de la Biosfera Ría Celestún, entre Yucatán y Campeche. Lo anterior desató el enojo de varias personas de la localidad, en particular de los camaroneros y de las familias de los detenidos.

El 29 de mayo de 2002, aproximadamente 500 personas se reunieron en la plaza, afuera de la Presidencia Municipal de Celestún para pedir la libertad de los pescadores detenidos; responsabilizaron a la dirección de la Reserva por el incidente y reclamaron que, a pesar de las restricciones impuestas a la pesca de camarón, ésta es parte de los "usos y costumbres" de la comunidad. Los manifestantes impidieron el acceso a Celestún al personal de la Reserva, al de otras Organizaciones No Gubernamentales (Batllori, 2003: 92-93). "Desde entonces el gobierno de Yucatán tuvo que prohibir la pesca de camarón. Más bien tuvo que hacer efectiva la prohibición mientras se solucionaba el conflicto. Mientras los turisteros seguían dando sus paseos". Después, "hubo un día que a mí me tocó [observar cómo] casi se matan entre ellos, y que los camaroneros dijeron que cerraban la entrada de los turistas porque decían: uno, la ría es para la pesca, y dos, si se cierra para la pesca se cierra para todos, entonces no pasan los turistas tampoco. Estuvo fortísimo. Entonces cerraron la ría, y la verdad uno de los lancheros, mis respetos, porque se vio muy buen negociador y habló con ellos [los pescadores] "camaradas que nosotros los apoyamos, todos somos Celestunenses" y entonces bueno, se solucionó la cosa, pero ya habían cerrado la entrada a Celestún, y había paradójicamente turismo que llegaba pero lo paraban con el mismo argumento: "si yo no pesco tu no llevas turistas"'(miembro Pronatura, entrevista en Mérida)

Tras largas negociaciones, el turismo volvió a la normalidad en ese mismo día pero la pesca siguió siendo monitoreada en el nombre de la conservación de la naturaleza.

19 de Julio 2002. El conflicto estalla de nuevo cuando los pescadores de Celestún unidos a los lancheros 
turísticos abordan el barco de la Armada y secuestran a sus tres navegantes. Los lancheros y los pescadores acusan a los soldados de "un comportamiento irresponsable de cara a la conservación del flamenco rosa". De acuerdo a los lancheros, los soldados están navegando demasiado cerca de las aves, de tal modo que las asustan y las obligan a volar, ahuyentándolas. Esta situación, consecuentemente, preocupa a los turistas y hace que menos personas quieran tomar el paseo en la lancha para ver a unos flamencos que no están. Los lancheros y los pescadores demandan la liberación de los nueve pescadores de Celestún todavía detenidos en Campeche como cambio para liberar a los soldados secuestrados. La respuesta del gobierno federal no se hace esperar y en cuestión de horas los militares sitian Celestun. Llegan al puerto 500 policías federales y estatales, tres secciones del Cuerpo de la Marina y varios helicópteros (La Revista Peninsular, 2002). Después de discusiones con un enviado del gobierno federal, los pescadores y lancheros liberan a los soldados y el turismo vuelve a la normalidad al día siguiente. La pesca de camarones en la ría, ilegal en el papel, se practica de nuevo en la ría, y unos días después, los pescadores detenidos son liberados sin cargos. Un poco después, el barco de la Armada de México desaparece de la ría de Celestún y la pesca deja de ser desde entonces, monitoreada.

La escala y respuesta militarizada ante lo que podría considerarse como un conflicto pesquero de interés regional señala la importancia del espacio de la ría y sus recursos - pescado, flamencos, turistas- a nivel nacional e internacional. Esta disputa desvela una serie de agentes (lancheros, pescadores, soldados, ONGs, instituciones científicas, turistas) y su lucha por ocupar, apropiarse y usar la ría como un sitio de pesca, como un sitio de conservación y como un resort ecoturístico.

Para poder comprender las raíces de este conflicto es necesario saber que, a pesar de su inscripción en una Reserva de la Biosfera, en Celestún, el 80\% de la población sigue viviendo exclusivamente de la pesca. Celestún ha sido tradicionalmente un puerto pesquero y es actualmente el segundo puerto pequero más grande de la península de Yucatán. Prohibiciones masivas a la pesca siguieron muy de cerca a la conservación del área a principios de los años ' 80 s. Estas prohibiciones respondían a la preocupación global inherente al concepto de protección de la biodiversidad, por preservar recursos naturales escasos. En Celestún las prohibiciones respondieron explícitamente a una supuesta sobre-explotación de los recursos pesqueros, fundamentalmente pulpo y camarón rosado, causada por "capturas insostenibles, masivas e irresponsables" (Semanart, 2000). Como resultado de lo que se calificó como "ilícitos ambientales" (Ibíd.) se impusieron una serie de vedas y se introdujo la estacionalidad en la actividad pesquera: la pesca de pulpo se restringió a los meses de agosto a diciembre y la pesca del camarón rosado, en la ría, quedó totalmente prohibida. Una de las razones fundamentales de la prohibición, no explícita hasta más tarde, fue que el camarón rosado es la base fundamental de la comida del flamenco, la principal especie en conservación pero también, el principal atractivo turístico puesto en valor de la Reserva de la Biosfera.

Irónicamente, la pesca masiva de esta especie había sido alentada por el gobierno estatal y federal en respuesta directa a la crisis del henequén a finales de los años '70s. Como ha sido ampliamente recogido, la promoción del sector pesquero a nivel estatal estuvo acompañada en Celestún por la llegada masiva de población del interior guiada estatalmente a través de programas como La Marcha al Mar que, tal y como recogen los habitantes celestunenses, "traían a campesinos para ser pescadores regalándoles las embarcaciones y los utensilios de pesca". En los años ' $80 \mathrm{~s}$ y ' 90 s estas políticas generaron movimientos masivos de migraciones laborales desde el interior hasta municipios como Celestún donde la población dependía exclusivamente de la pesca para su sustento y donde además, y en virtud a las máximas de conservación impuestas por la Reserva, esta actividad pasaba a estar fuertemente controlada y restringida (Cervera y Fraga, 2003). Como resultado, entre las décadas de 1970 y 1990 y precisamente en el momento álgido de conservación del área, Celestún casi cuadriplicó su población llegando a crecer a un ritmo superior al 5\%. En el año 2003, la pesca de camarones afectaba al $90 \%$ de la comunidad (Batllori, 2003), un número que nos ayuda a contextualizar la frase que encabeza este conflicto, "a la cárcel por pescar para comer".

Las políticas de Marcha al Mar supusieron para Celestún el fortalecimiento de las tendencias privatizadoras de la actividad pesquera ya evidentes en el conjunto regional, pero también, el establecimiento 
de un sistema de poder municipal con claros rasgos caciquiles y ordenado en función de unos pocos empresarios pesqueros (permisionarios) y una población altamente dependiente. Este sistema de poder se configuraría en el puerto en un mediador crucial de la actividad desarrollista al monopolizar bajo su control casi exclusivo todo el proceso pesquero: desde la captura del producto hasta su comercialización y exportación.

La realidad pesquera de Celestún es totalmente velada en el imaginario turístico de la comunidad como parte de una Reserva de la Biosfera. En este imaginario turístico, Celestún aparece representado como un pequeño y pintoresco puerto pesquero, un resort pacífico y un santuario exclusivo del flamenco rosado donde a parte de los guías turísticos de la ría, los lancheros, también conocidos como turisteros, no pueden observarse trazos de vida humana (Yucatán Today, 2009). Desde su puesta en marcha, el ecoturismo, como hemos visto, es una actividad totalmente dependiente de la presencia del flamenco rosa en la ría de la comunidad. Esta se limita a los meses de octubre a febrero de cada año. En estos meses, se estima que la ría recibe más de 200.000 turistas. La mayor parte de estos turistas forman parte de paquetes turísticos de la Riviera Maya y de Mérida y una vez en la comunidad, todos los que llegan dan el paseo para ver al flamenco en la ría. Su objetivo: poder fotografiar al flamenco en vuelo, y poder, si no tocarle, al menos verle desde una distancia muy corta. Estas prácticas han atraído y han concentrado enormes flujos de turistas en el espacio de la ría precisamente cuando el flamenco hace uso del mismo. Con ello, el ecoturismo ha puesto más presión no sólo sobre este espacio y sus recursos naturales sino también sobre los pescadores que, como muestra el conflicto narrado, hacen uso de este espacio como lugar de trabajo.

Paradójicamente además, el ecoturismo no solo ha concentrado los flujos turísticos en la ria para contemplar al flamenco rosa sino que además ha sido una actividad que ha atado de un modo todavía más fuerte a los pescadores, nativos y foráneos, a este espacio. Esto se debe principalmente al hecho de que desde la promoción del destino como uno de los destinos alternativos a las playas del Caribe Mexicano, los camarones rosados se han convertido en una de las especies favoritas de consumo turístico a nivel local. La demanda turística sostenida de camarones servidos en ceviche y cocktails en los restaurantes de la playa y cantinas del municipio constituye un gran incentivo para la población del interior de la península que se desplaza a la comunidad. Sólo entre 1990 y el año 2000, la inmigración por motivos de trabajo al puerto se incrementó en un $87 \%$ (INEGI, 2005), todos los recién llegados prefieren, por su origen campesino, pescar camarones en la ría antes de aventurarse a pescar el pulpo en el mar. A través de la creación de esta demanda sostenida, el ecoturismo no sólo ha contribuido indirectamente a la pesca ilegal de esta especie en la comunidad sino que se ha convertido en una fuerza fundamental detrás de los flujos migratorios no regularizados a un área natural protegida que ya estaba superpoblada.

$\mathrm{Al}$ tratarse de una actividad fomentada dentro de los límites de un área natural protegida, el ecoturismo ha atraído una serie importante de ONGs conservacionistas y de desarrollo así como de instituciones de investigación como la Pronatura Yucatan, la Agencia Japonesa de Conservación, la Universidad Autónoma de México, el Centro de Investigaciones y Estudios Superiores de Mérida o el Centro de Investigación Científica de Yucatán entre otros. Para estas instituciones la ría y sus recursos naturales son un laboratorio privilegiado para realizar proyectos de investigación en materia conservacionista. Estas instituciones hacen un uso estratégico de la ría y de la función de conservación de la Reserva que antes mencionaba y han conseguido atraer grandes cantidades de capital a la ría. Generalmente este capital se traduce en proyectos de monitoreo de las especies de flora y fauna de la ría y de las actividades pesqueras en este espacio. Además, y siguiendo la función de desarrollo de las Reservas de la Biosfera, el gobierno federal ha delegado en la ONG Pronatura Yucatán la tarea de velar por el ecoturismo como una práctica de desarrollo sostenible en la comunidad. Con este propósito Pronatura Yucatán pero también otras ONGs como la Agencia Japonesa para la Conservación han estado trabajando en cursos de capacitación dirigidos casi en exclusividad al grupo de los lancheros de la ría. Este colectivo se ha convertido, como muestra el conflicto narrado, en un grupo cardinal en la articulación de la ría como un espacio de inmovilidad y confrontación con los dictados de conservación y desarrollo impuestos por la Reserva.

En Celestún, sólo pueden prestar el servicio turístico de visita al flamenco las lanchas o embarca- 
ciones pertenecientes a las cooperativas de lancheros turísticos federadas desde 1996 en la Federación Turística de Lancheros Unidos de Celestún. En la federación constan siete cooperativas que se estima que dan trabajo a 85 lancheros (SEMARNAT, 2003: 36). De ellas, cuatro operan desde la ría, y las tres restantes lo hacen desde la playa.

Los lancheros del lado de la Ría, o los lancheros de la ría como les conocen en el municipio, cuentan con 57 socios constituidos en cuatro Sociedades de Solidaridad Social. Estas sociedades trabajan en conjunto con el Patronato federal CULTUR que les brinda infraestructura y administra la actividad. De las 57 embarcaciones que manejan, 31 son alquiladas a uno de los permisionarios pesqueros de la comunidad, y 26 son embarcaciones propias. Atendiendo al Plan de Manejo de la Reserva, los lancheros de la ría absorben el 95\% del turismo que llega al puerto. Los servidores del parador de la Ría han recibido apoyo de créditos por parte de diferentes instituciones del gobierno de Yucatán y también del gobierno federal para la adquisición de lanchas y motores; para el desazolve de manantiales o canales de importancia en el recorrido Reserva apoyado a través del Programa de Empleo Temporal; cursos de capacitación como guías turísticos $\mathrm{y}$, asimismo, se han realizado cursos de inglés a través la organización de Pronatura.

Los lancheros del lado de la ría son un colectivo fundamental en el mantenimiento o ruptura de la realidad de Celestún como un destino ecoturístico a nivel internacional. No sólo se han apropiado estratégicamente del espacio de la ría sino también de los discursos globales relativos a la conservación de la biodiversidad y el desarrollo de un turismo sostenible con el medio, con el fin del promover intereses locales, fundamentalmente asociados a la pesca. Esta apropiación es evidente en el conflicto narrado por ejemplo, cuando los lancheros justifican la expulsión del barco de la Armada aduciendo un comportamiento irresponsable de cara a la conservación del flamenco rosa o por ejemplo, cuando conocedores de la importancia de la ría para el gobierno federal deciden cerrar este espacio suspendiendo con ello los flujos turísticos a la comunidad.

El conflicto no sólo muestra los efectos problemáticos de la inscripción de una comunidad concreta en el proyecto biopolítico de las Reservas de la Biosfera, o cómo el diseño de nuevas estrategias de poder/saber sobre la vida animal, vegetal y humana codifican y regulan el espacio de la ría de acuerdo a los dictados globales de la conservación y el desarrollo sostenible a través del ecoturismo, sino que muestran además, la gestación de nuevas relaciones de poder local y la apropiación y poder transformador de estas codificaciones. El conflicto repasado muestra en este sentido, cómo la inclusión de la ría en la Reserva de la Biosfera alteró un espacio local al convertirlo en un punto de paso obligado para diferentes flujos de personas, objetos, intereses, capital y recursos. La globalización de la ría por decirlo de algún modo, transformó este espacio en un hotspot (Córdoba Azcárate, 2010), en un espacio de permanencias y conflictos poblado de actores locales y globales- instituciones formales e informales, $\mathrm{ONG}$, pescadores natos, inmigrantes, lancheros y turistascon intereses muchas veces encontrados. La lucha por mantener un sitio en la ría, por ocupar el lugar, resulta crucial no sólo para beneficiarse de los recursos globales canalizados a la comunidad a través de la conservación y el turismo, o para "salvar" ese "espacio de valor" al que se refería Escobar (1996) sino también, para redefinir y controlar jerarquías de poder a nivel local. Esto es precisamente lo que está en juego en este conflicto cuando los lancheros y los pescadores luchan primero entre ellos pero luego juntos contra las instituciones conservacionistas y el gobierno e incluso su rama militar, para convertirse en los guardianes de la ría y controlar de este modo la distribución local de los beneficios globales canalizados hacia este espacio desde su inclusión en un área protegida. Este conflicto muestra además cómo las movilidades globales están siempre acompañadas de la lucha por parte de diferentes agentes por ocupar esos espacios concretos donde los flujos globales se concentran. Algo muy similar ocurre, como vamos a ver a continuación, con el espacio de la playa, el otro gran espacio de (in)movilidad y conflicto generado por el proyecto biopolítico de la Reserva de la Biosfera.

\subsection{En la playa: "la playa no es un espacio privado"}

El siguiente conflicto tuvo lugar en el palacio municipal de Celestún y pude presenciarlo personalmente durante mi trabajo de campo en el área. He elegido este conflicto precisamente por su naturale- 
za ubicua y porque pasando más de unas horas en la comunidad es perfectamente posible presenciar un evento similar. Este conflicto describe fundamentalmente la lucha de diferentes mujeres por el uso del espacio de la playa como un lugar de trabajo e ilustra de una manera bastante palpable la condensación de las movilidades globales de turistas, capital y trabajo a través de la dinámica de apropiación espacial. Concretamente, esta disputa visibiliza la transformación de la playa en un espacio vívido, dinámico y conflictivo donde agentes locales luchan por permanecer inmóviles tras la declaración del área como área natural protegida así como la puesta en marcha de nuevos sistemas de codificación de las relaciones hombre-medio en la comunidad. El siguiente extracto forma parte de mis notas de campo y diario etnográfico y recoge conversaciones literales tal y como fueron anotadas en ellos.

El 24 de marzo de 2005, a las 10 am en el palacio municipal, en plena temporada turística, el traslado forzoso al palacio municipal de unas vendedoras de artesanías de Chiapas y sus hijos pequeños por parte de dos artesanas de concha y caracol que venden en la playa, desata una fuerte discusión.

Artesana playa: "las chiapanecas no pueden vender aquí (...) que se vayan a otro lado (...) nos quitan los pesos que ganamos (...) y siempre es igual"

Concejala de ecología y responsable mujer en el palacio: "son mujeres y tienen el mismo derecho que tú. La playa no es de nadie, no es privada y no puedes echarlas (...) es un abuso y no venden lo mismo que ustedes"

Las artesanas de la playa pasan directamente a hablar con el presidente municipal. Después de 10 minutos salen y exclamando "nos volvemos al trabajo" abandonan el palacio. Tres cuartos de hora después, el presidente municipal zanja el conflicto. Se asoma, llama a la concejala y exclama en voz bastante alta: "Prefiero tener contentos a los celestunenses, mejor que se vayan los de fuera".

Con sus niños a cuestas, y tras el dictamen del presidente, las tres chiapanecas que en todo este proceso sólo se han entendido con señas toman el autobús de línea que las saca del municipio en dirección a Mérida sin haber vendido hoy ninguna de sus mercancías (Extracto de diario de campo, Celestún DDC 2, Marzo 2005)

Las playas del Golfo de México no son tan bellas como las playas de lado caribeño, pero son todavía un reclamo turístico importante en la Península de Yucatán. Estas playas de aguas más turbias, arena más rugosa y un viento constante, son un importante referente en el turismo regional y nacional que encuentra en ellas precios todavía asequibles para poder comer pescado fresco de alta calidad en un restaurante frente al mar.

Desde que Celestún fue declarado un área natural protegida y el ecoturismo implementado como medida de desarrollo para la población, la playa, junto a la ría, ha sido el otro gran nodo central objeto de nuevas codificaciones y regulaciones. De más de 10 kilómetros de largo, la playa ha sido radicalmente transformada. Hacia el este, la playa forma parte del área de amortiguamiento de la Reserva tal y como fue delineado en el Plan de Manejo. Junto a la ría este área es una de las más intensamente monitoreadas y controladas por la dirección de la Reserva así como por las instituciones de investigación y ONGs conservacionistas trabajando en la comunidad ya que es el área favorita de anidación de la tortuga carey. Hacia el oeste, la playa yace llena de algas acumuladas en la orilla y un paisaje de naves industriales abandonadas que antes estaban íntegramente dedicadas a la industria harinera- una parte importante de la historia de la comunidad en los años ' 80 s-. Esta parte de la playa concentra el mayor número de asentamientos irregulares de población en la comunidad, generalmente habitados por campesinos del interior de Yucatán y sus familias que se trasladan estacionalmente a la comunidad en busca de trabajo en la pesca, así como los mayores vertederos ilegales de basura de pescado en la costa. Esta área de la playa desprende un fuerte olor que mantiene alejados a los turistas, a la población nativa de Celestún y también, a las instituciones de desarrollo y conservación.

Entre un área y otra se abre un pequeño espacio de un kilómetro de largo y pocos metros de ancho que concentra la infraestructura turística de la comunidad que se reduce a unos pocos restaurantes y algunos hoteles locales. Este kilómetro de playa está situado entre las desembocaduras a la playa de las calles 11 y 12 y es precisamente aquí donde, después de la ría, se concentran y se articulan los flujos 
globales de turistas y capital de un modo abrumador.

Los autobuses de los itinerarios ecoturísticos llegan a las calles 11 y 12 después de haber parado en la ría para hacer el paseo y ver al flamenco. Allí aparcan durante algunas horas mientras los turistas comen en los restaurantes que han sido previamente contratados por las agencias de viajes. Esta práctica ha creado el bien definido y estructurado itinerario turístico de la ría a la playa sin paradas intermedias. La llegada de los autobuses turísticos a las calles 11 y 12 y las mareas de turistas desde estas calles hasta la playa, sumadas a la concentración de los hoteles y restaurantes de la playa en este reducido kilómetro entre las dunas protegidas al este y los asentamientos de población irregular al oeste, ha contribuido enormemente a que también sea en este espacio donde diferentes colectivos informales se concentren y luchen por el acceso a los turistas y por ende, a una fuente alternativa de ingresos. Estos colectivos informales incluyen un grupo de lancheros que ofrecen paseos irregulares en lancha para ver al flamenco en la ría; las conocidas como artesanas de la playa, y una serie de vendedores ambulantes de hamacas y de pasteles. Más recientemente, la playa de Celestún se ha convertido también en una de las paradas de pequeños grupos o parejas de mujeres de Chiapas y sus hijos que, huyendo del conflicto armado y de la situación de pobreza extrema de sus comunidades de origen, buscan en los destinos turísticos del estado de Yucatán y Campeche una salida económica, una oportunidad para una vida mejor. Estas mujeres, tal y como la disputa que he recogido más arriba muestra, son generalmente expulsadas de la comunidad por las artesanas de la playa, un grupo de mujeres nativas que trabaja la artesanía de concha y caracol y que se han convertido en las guardianas y reguladoras de facto del acceso y uso de este espacio en la comunidad.

Las artesanas de concha y caracol constituyen un reducido grupo de 25 mujeres casi todas relacionadas por parentesco con los lancheros de la ría o con los de la playa. Estas mujeres están organizadas desde el año 2009 en cuatro sociedades, la Sociedad Danza de los Flamencos, la Sociedad Paso del flamenco, la Sociedad las Bahías de las Gaviotas; la Sociedad Mayan-Walcane y la Sociedad Arrecifes y Corales que se reparten en tenderetes informales pero estables sobre los accesos principales a la playa. Las dos primeras, usando el nombre del flamen- co y las más influyentes, ocupan las calles 11 y 12 por donde entran los turistas de viajes organizados a los restaurantes; la tercera está justo en frente del restaurante La Palapa, a unos pocos metros del acceso a la playa de la calle 12 y la cuarta se ubica en la calle anterior al muelle. Durante los últimos años estas mujeres se han ido apropiando gradualmente de casi todos los accesos a la playa así como del tramo de playa que va desde los mismos hasta la orilla del mar. Esta apropiación del espacio se materializa en 20 pequeños y muy rudimentarios puestos de venta de recuerdos turísticos y a través del ejercicio de una vigilancia constante. Durante las temporadas turísticas, como pascua o las vacaciones de verano, estas mujeres pasan el día entero con sus hijos inmovilizadas en sus puestos de venta. Cada mañana, alrededor de las 5 am toman sus trici-taxis y bicicletas amontonadas con los objetos de venta para los turistas, las mesas, sombrillas, sillas y comida para pasar el día en la playa. Una vez en la playa montan sus puestos, y uno a uno despliegan los recuerdos fijándolos fuertemente a las mesas para evitar que el viento se los lleve. Mientras esperan a los turistas las artesanas vigilan la playa en busca de vendedores de fuera de la comunidad. Si alguno es detectado y con ayuda de los lancheros de la playa, y si es necesario, de los lancheros de la ría, los expulsan de la playa. Este control del espacio se realiza a lo largo de todo el día, de una manera muy sutil y es una práctica que ha sido incorporada como un hábito en estas mujeres e incluso en sus hijos para quienes muchas veces de lo que ganan aquí depende que puedan o no comer ese día.

Las artesanas de concha y caracol viajan por turnos a Mérida una vez cada dos semanas para proveerse en las tiendas del centro de la ciudad del material que necesitan para elaborar collares, pulseras y recuerdos. Luego, confeccionan en sus casas los recuerdos turísticos con innumerables variaciones y siempre fuera de la vista de las artesanas de otras sociedades para poder llamar la atención del turista sobre su puesto a su entrada en la playa. A pesar de la concentración de turistas y capital en este reducido espacio, las ventas de las artesanas de la playa son muy pobres y no exceden normalmente los 50-100 pesos mexicanos en un buen día. Esta situación, ha generado en estas mujeres lo que un técnico de desarrollo calificaba como un "fuerte sentido de exclusividad en el ejercicio de las actividades productivas 
ligadas al turismo" que hace que se comporten como si el espacio de la playa fuera un espacio privado. Este sentido de competitividad y confrontación con otros posibles competidores así como la apropiación del espacio de un modo tan materialmente visible se suma al hecho de que a través de esta apropiación las artesanas han sabido articular intereses personales y demandas políticas clave. Las artesanas son conscientes del lugar que ocupa la playa tanto en las medidas conservacionistas del área como en los itinerarios ecoturísticos y por ende de la importancia de este espacio para las autoridades locales sino también estatales y nacionales como generador de capital internacional. Aliadas con los colectivos de lancheros de la ría y de la playa, las artesanas movilizan a las autoridades locales en su favor a través de un intercambio político de favores. Las autoridades locales, conscientes de los lazos de parentesco que unen a estas mujeres con los lancheros y a estos con los flujos de capital internacional así como de la importancia de la playa como un núcleo de conservación y un reclamo turístico a nivel internacional, generalmente optan por mediar en estos conflictos a favor de este colectivo de mujeres contribuyendo, al hacerlo, a asegurar el control de los flujos globales de turistas y capital por parte de determinados sectores de la población y reproduciendo así nuevas dinámicas de exclusión y desigualdad.

Ciertamente, igual que la ría, la playa de Celestún emerge como un espacio fragmentado a raíz del proyecto biopolítico de la Reserva de la Biosfera. Y sin embargo, este conflicto, igual que el anterior muestra la naturaleza paradójica de los procesos de producción biopolítica, su naturaleza situada y su articulación a través de prácticas de movilidad concretas. A pesar de recibir grandes números de turistas internacionales, de recursos y capital después de su transformación en un espacio natural protegido, sólo unos pocos colectivos en la comunidad -los lancheros, los 'restauranteros', las artesanas- obtienen beneficios directos de ellos. Estos beneficios están directamente ligados a ganar la proximidad física al turista que sólo puede ocurrir en la ría y en la playa. La disputa de las artesanas ilustra la pugna de algunos habitantes de Celestún así como de poblaciones vecinas altamente empobrecidas, por acceder y ocupar este espacio en el que los recursos globales se han concentrado. La concentración de servicios en esta pequeñísima área de la playa y la pelea por apropiarse y redefinir este espacio son algunos de los efectos que la articulación de Celestún como un destino ecoturístico a nivel internacional ha tenido a nivel local. La apropiación de este espacio estratégico de la playa permite a las artesanas, como este caso demuestra, controlar de facto el acceso de otros colectivos a la playa así como su cercanía a los turistas y mantener en su poder los escasos beneficios derivados de la actividad turística en la comunidad.

\section{CONCLUSIONES}

La biodiversidad, señalan Quijano Valencia y Tobar (2006: 13), "es un campo de alta conflictualidad en el cual se debate el control de los espacios biofísicos y socio-culturales". En este artículo hemos repasado con evidencia etnográfica algunas de las prácticas sociales a través de las cuales este control se ejerce en el espacio concreto de una Reserva de la Biosfera entendida como un claro proyecto biopolítico.

Las políticas de conservación y de desarrollo turístico asociadas al proyecto biopolítico de la Reserva de la Biosfera Ría Celestún han reestructurado los espacios de la ría y de la playa de la comunidad en espacios de (in)movilidad y conflicto donde los flujos globales de personas, trabajo y capital se condensan y donde diferentes colectivos pugnan por ocupar un lugar. Estos espacios de (in)movilidad emergen como algo más que micro espacios disciplinados ordenados a través de la lógica y los imperativos globales de la conservación y el desarrollo a través del ecoturismo asociados desde los años '90s al discurso político y cultural de la biodiversidad. En estos espacios, la naturaleza desigual, condensada y espacialmente demarcada de la producción biopolítica y su nexo con la movilidad quedan de manifiesto.

Como hemos visto, en una comunidad con más de seis mil habitantes, inscrita en una Reserva de la Biosfera de más de 80.000 hectáreas, sólo dos puntos concretos se han beneficiado de los flujos globales de capital y recursos canalizados a través del turismo y la conservación al área. Fuera de estos dos espacios puede decirse que Celestún permanece al margen de la globalización y de sus beneficios. Es precisamente esta exclusión espacial lo que hace que la lucha por permanecer inmóviles en la ría y 
en la playa como esos espacios de (in)movilidad sea tan importante. Colectivos de población concretos, los lancheros y las artesanas, se han convertido en los guardianes de estos espacios, de su acceso y del control sobre sus recursos. Las luchas cotidianas por un lugar en estos espacios muestran no sólo la naturaleza conflictiva y contradictoria de los dictados de conservación y de desarrollo a través del turismo, sino también el potencial transformador implícito en la producción biopolítica de generar formas de vida alternativas. Lancheros y artesanas se han apropiado estratégicamente de los espacios de la ría y de la playa como esos "espacios de valor" donde la nueva codificación y regulación de las relaciones hombremedio impuesta por los imperativos globales de la conservación de la biodiversidad, es más evidente. Estos colectivos han sabido movilizar los referentes asociados a la biodiversidad del área no ya para "salvar" la naturaleza, sino para defender intereses locales. En esta defensa, tal y como hemos visto en ambas disputas, estos colectivos están mostrando poseer una fuerza creativa y confrontacional con los procesos institucionales de codificación y regulación propios de una Reserva de la Biosfera.

\section{AGRADECIMIENTOS}

Me gustaría agradecer sus valiosos comentarios para este texto a Carlos de Castro, Fernando D. Rubio e Ignacio Mendiola.

\section{BIBLIOGRAFÍA}

Baerenholdt, O. Haldrup, M., Larsen, J., Urry, J. (2004): Performing tourist places, Aldershot, Ashgate. Batllori Sampedro, S.E. (2003) "Pesquerías artesanales de camarón y derechos humanos" Recursos de Manejo Costero 16: 85-116.

Bergmann, S. and Sager, T. (Eds.) (2008): Ethics of Mobilities: Rethinking Place, Exclusion, Freedom and Environment, Aldershot, Ashgate.

Cervera, J. and Fraga, J. (2003) "Una aproximación a la construcción de un paisaje costero en el área maya”, en P. Colunga and A. Larque (Eds.): Naturaleza y Sociedad en el Área Maya, Mérida, Yucatán, Centro de Investigación Científica de Yucatán.

Córdoba Azcárate, M. (2010) "Contentiuos hotspots: Ecotourism and the restructuring of place at the Biosphere Reserve Ria Celestun" Tourist Studies 10 (2): 99-116.

Córdoba AzcÁrate, M. (2006) "Between Local and Global, Discourses and Practices: Rethinking Ecotourism Development in Celestún (Yucatán, México)" Journal of Ecotourism 5: 97-111.

Córdoba Ordóñez, J., García de Fuentes, A., Córdoba Azcárate, M., Ayala Arcipreste, ME. (2004) "Efectos locales de políticas globales: Celestún y "su" reserva de la biosfera (Yucatán, México)" Anales de Geografia de la Universidad Complutense 24:55-78.

Escobar, A. (1996): Pacífico ¿Desarrollo o diversidad?. Estado, capital y movimientos sociales en el Pacifico Colombiano, Bogotá, Cerec-Ecofondo.

EscoBAr, A. (1998) "Whose knowledge? Whose nature? Biodiversity conservation and the political ecology of social movements" Journal of Political Ecology 5: 53-82.

Escobar, A. (2008): Identidad, territorio y cultura: La ecología política de las comunidades negras del Pacifico colombiano, México, Programa de las Naciones Unidas para el Medio Ambiente.

Duffy, R. And Moore, L. (2009) "Neoliberalising nature? Elephant-Back Tourism in Thailand and Botswana" Antipode 42 (3): 742-766.

Foucault, M. (2006): Historia de la sexualidad I: La voluntad de saber, Madrid, Siglo XXI.

Foucault, M. (2008): Seguridad, territorio, población, Madrid, Akal.

Foucault, M. (2009): Nacimiento de la biopolítica, Madrid, Akal.

Hardt, M. y Negri, A. (2002): Imperio, Barcelona, Paidós.

HaRdT, M. y Negrí, A. (2004): Multitud, Madrid, Debate.

HarveY, D. (1996): Justice, nature and the geography of differences, Oxford, Blackwell.

Harvey, D. (2006): Spaces of global capitalism. Towards a theory of uneven geographical development, London, Verso. 
Instituto Nacional de Estadística Geografía e Informática, INEGi (2005) Anuario Estadístico de Yucatán, Aguascalientes, México, INEGI.

Instituto Nacional de Estadística Geografía e Informática, INEGI (2008) Anuario Estadístico de Yucatán, Aguascalientes, México, INEGI.

JAmal, T. And STRONZA, A. (2008) "Dwelling' with ecotourism in the Peruvian Amazon: Cultural relationships in local—global spaces', Tourist Studies 8(1): 313-335.

KRÜGER, O. (2005). "The role of ecotourism in conservation: panacea or Pandora's box?" Biodiversity and Conservation, 14(3): 579-600.

La Revista Peninsular (2002) “Crónica de un conflicto anunciado: estalla la violencia en Celestún”, La

Revista Peninsular [Online] En: http://www.larevista.com.mx/ [Accedido 19 Julio 2009].

Méndez-Contreras, J. Dickinson, F. and Castillo-Burguete, T. (2008) "Community member viewpoints on the Ria Celestún Biosphere Reserve, Yucatán, México: Suggestions for improving the community/ natural protected area relationship", Human Ecology 36:111-123.

Mendiola, I. (2006): El jardín biotecnológico: tecnociencia, transgénicos y biopolítica, Madrid, La Catarata.

Myers, N. (2001) "Hotspots", en Levin, S. A. Encyclopedia of Biodiversity (vol. 3) San Diego, Academic Press.

PARK, J. (2003) "Disciplining mobility. Governing and safety", en Bratich, J.Z., Packer, J. and Mccarthy, C. (Eds.): Foucault, cultural studies, and governmentality. Albany, State University of New York Press, $135-163$

Pronatura (1999): Aspectos de la actividad turística en la Reserva de la Biosfera Ría Celestún, Península de Yucatán, Unidad Mérida, Pronatura.

Quijano Valencia, O., Tobar, J. (Eds.) (2006): Territorios del saber. Biopolítica y filosofías de vida, Popayán, Colombia, Universidad del Cauca.

RAMSAR List (2010) “The List of Wetlands of International Importance” (22 Junio 2010)' [Online] En: http:// www.ramsar.org/cda/en/ramsar-about-sites/main/ramsar/1-36-55_4000_0_ [Accedido 28 Julio 2010]

Revista Opcion (2009) "Expulsan a Pescadores de Celestún"”, Revista Opción [Online] En: http:// revistaopcion.blogspot.com/2009/10/expulsan-pescadores-de-celestun.html [Accedido 6 Octubre 2009].

Robinson, M. And Smith, M. (2006) "Politics, power and play: the shifting contexts of cultural tourism", en M. Smith and M. Robinson (Eds.): Cultural Tourism in a Changing World. Politics, participation and (re) presentation, Cleavedon, Chanel View Publications, 1-18.

Secretaria de Medio Ambiente y Recursos Naturales SeMARnAT (2000) Programa de manejo de la Reserva de la Biosfera Ría Celestún, México, DF, Comisión Nacional de Áeas Protegidas.

Sevilla Buitrago, A (2010) "Urbanismo, biopolítica, gubernamentalidad: vida y espacio en la renovación de los estudios urbanos", Boletín Ciudades para un Futuro más Sostenible, 44 (s.p.), En: http://habitat. aq.upm.es/boletin/n44/aasev.html (Accedido 30 Diciembre 2011).

Sheller, M. And Urry, J. (Eds.) (2004): Tourism Mobilities. Places to play, places in play, London, Routledge.

Sheller, M And Urry, J. (2006) “The new mobilities paradigm”, Environment and Planning A 38(2): 207226.

Sмiтн, N. (2008): Uneven development: nature, capital, and the production of space, London, University of Georgia Press.

UNESCO (1979) "Man and Biosphere Program. Biosphere Reserves" [Online] En: http://portal.unesco. org/science/en/ev.php-URL_ID=4801\&URL_DO=DO_TOPIC\&URL_SECTION=201.html [Accedido 24 Julio 2009].

UNESCO (2009) "Biosphere Reserves" [Online] En: http://portal.unesco.org/science/en/ev.php-URL

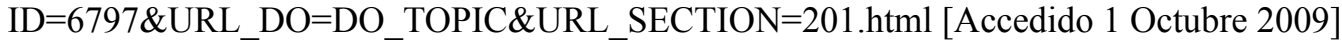

YuCATÁn Today (2009) "The tourist guide to Celestún", Yucatán Today [Online] En: http://Yucatántoday. com/en/topics/celestun [Accedido 1 Octubre 2009] 